\title{
Transcortical Selective Amygdalohippocampectomy in Temporal Lobe Epilepsy
}

\author{
André Olivier
}

\begin{abstract}
Numerous studies of the electrophysiology and neuropathology of temporal lobe epilepsy have demonstrated the mesial temporal structures to be the site of seizure origin in the majority of cases. This is the rationale for a transcortical selective approach, first introduced by Niemeyer, for removal of the hippocampus and amygdala. Series from a number of centers have demonstrated the efficacy of selective amygdalohippocampectomy compared to a more traditional resection. The technique described here and used at the Montreal Neurological Institute (MNI) utilizes a strictly endopial resection of the hippocampal formation and amygdala in addition to computer image guidance to perform the procedure. Ninety-five percent of patients at the MNI who underwent selective amygdalohippocampectomy realized a cessation of seizures, or greater than $90 \%$ reduction, with minimal risk of complications.
\end{abstract}

RÉSUMÉ: L'amygdalohippocampectomie sélective transcorticale dans l'épilepsie temporale. Plusieurs études électrophysiologiques et neuropathologiques de l'épilepsie temporale ont démontré que les structures temporales mésiales sont le site d'origine des crises dans la majorité des cas. C'est la justification de l'approche sélective transcorticale introduite par Niemeyer pour l'ablation de l'hippocampe et de l'amygdale. Des séries de cas de plusieurs centres ont démontré l'efficacité de l'amygdalohippocampectomie sélective comparée à une résection plus traditionnelle. La technique que nous décrivons ici et qui est utilisée à l'Institut neurologique de Montréal utilise une résection strictement endopiale de l'hippocampe et de l'amygdale sous guidage neuroradiologique pour effectuer l'intervention. Chez $90 \%$ des patients qui ont subi une amygdalohippocampectomie sélective à l'Institut neurologique de Montréal les crises ont disparu ou ont diminué de plus de $90 \%$ avec des risques de complications minimes.

Can. J. Neurol. Sci. 2000; 27: Suppl. 1 - S68-S76

Insight in the role played by the mesio-temporal structures in human epilepsy is derived from various sources. Hughlings Jackson ${ }^{1}$ was the first to describe the autopsy findings showing a mesio-temporal lesion as the cause of psychomotor seizures. Echoing the original observations of Jackson, the many experimental studies of the 1950 s such as those of Kaada, ${ }^{2}$ Vigouroux, ${ }^{3}$ Gastaut, ${ }^{4}$ Green, ${ }^{5}$ and the observations in the human by Feindel, ${ }^{6,7}$ Penfield and Jasper, ${ }^{8}$ and Morris ${ }^{9}$ pointed to a very important role of the mesiobasal temporal structures in experimental and human epilepsies.

There is a large collection of data describing striking neuropathological changes in the mesio-temporal area in patients with temporal epilepsy. The hippocampal sclerosis and mesiotemporal sclerosis, including changes in the amygdala, were reviewed in detail in a series of excellent studies. ${ }^{10-12}$ More recent work has shed light on the basic physiopathological mechanisms responsible for mesio-temporal epilepsy. ${ }^{13-20}$ Studies on mesio-temporal kindling have brought further comfirmation of the paramount importance of structures such as the uncus, amygdala, hippocampus, dentate gyrus, parahippocampus, entorhinal cortex, piriform and perirhinal areas in the genesis of temporal seizures. Modern tracing techniques have revealed the bewildering functional complexity of the above structures and the richness of their connections with each other and with the basal ganglia and neocortex..$^{15,19,21-23}$ From the surgical point of view it is important to realize that all these functional units are located in the mesiobasal part of the temporal lobe and represent, in part or in toto, the anatomical substratum of mesial temporal epilepsy.

\footnotetext{
From the Department of Neurosurgery, Montreal Neurological Hospital - Institute, Montreal, QC Canada.

Reprint requests to: André Olivier, Montreal Neurological Hospital, 3801 University Street \# 109, Montreal, QC H3A 2B4 Canada
} 
From the electrodiagnostic standpoint, recording with sphenoidal electrodes in patients with temporal lobe epilepsy has shown a predominance of discharges in the mesiobasal structures. $^{24}$ The paramount importance of these mesial structures was also confirmed by recording and stimulation with intracranial depth and surface electrodes. ${ }^{25}$ In our series of patients studied with stereotactic electrodes for bitemporal epilepsy, an overwhelming percentage of the seizures was found to originate in the limbic structures. ${ }^{26-34}$ These seizure discharges started either in the hippocampus or amygdala, but more frequently in the hippocampus, with rapid spread from one structure to the other. Simultaneous "regional" limbic onset in both amygdala and hippocampus was also frequent. Seizures of strict neocortical onset were rare. However, quick spread of the discharges to, and recruitment of, the neocortex was the rule. ${ }^{31,32}$

Stimulation studies, with stereotactic electrodes placed in neocortical and limbic structures of the temporal lobe have shown that many of the characteristic clinical features of temporal lobe epilepsy, including the patient's habitual aura can be reproduced by stimulation of the amygdala and hippocampus but rarely from the neocortical region. ${ }^{25}$ When electrical stimulation gave rise to seizures, these seizures were almost exclusively of limbic onset, slightly more often from the amygdala than from the hippocampus. These findings are also in keeping with our intraoperative stimulation results under local anaesthesia where the patient's habitual aura, psychic phenomena, automatisms and after discharges were mainly obtained from stimulation through the deepest contacts of depth electrodes corresponding to the amygdala and hippocampus (unpublished observations). They are also in keeping with the original work of Feindel et $\mathrm{al}^{6,7}$ on the peroperative stimulation of the amygdala region in man and with the results of Halgren ${ }^{35}$ using strictly limbic stimulation. That these phenomena can also be triggered by neocortical stimulation has also been shown by Penfield et al. ${ }^{8}$

Imaging studies of the past, such as pneumoencephalography very often showed enlargement of one temporal horn in temporal lobe epilepsy. ${ }^{24}$ Many of the characteristic changes described by the pathologists, particularly mesial temporal sclerosis and hippocampal atrophy, are routinely shown by MRI. ${ }^{36}$ Furthermore, MRI can reveal a variety of additional epileptogenic lesions such as gliomas, vascular malformations, and cortical dysplasias. Atrophic changes and volumetric assessments of these changes for specific structures can now be documented accurately with MRI. ${ }^{36}$

The syndrome of mesio-temporal lobe epilepsy has been reviewed recently by Wieser et al. ${ }^{37}$ The role of febrile convulsions in the pathogenesis of temporal epilepsy was stressed by Falconer ${ }^{38}$ and more recently by Abou-Kalil ${ }^{39}$ and Berkovic. $^{36}$ It is fair to say that the clinical manifestations of mesio-temporal epilepsy are, in large part, the same as those characteristics of "temporal lobe epilepsy", namely the presence of an aura, most often a hard to describe sensation, the alteration of consciousness with oral and manual automatisms, followed by amnesia for the episode. Finally, the studies of Wieser and Yasargil have shown that selective amygdalohippocampectomy (AHC) can provide results comparable to those of more traditional temporal resections. ${ }^{26,40,41}$

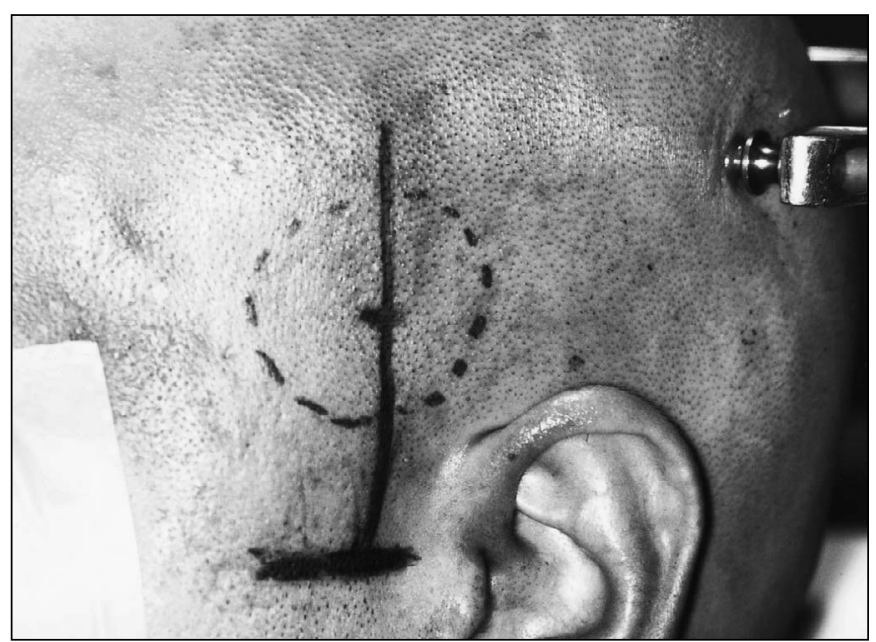

Figure 1: Scalp incision and craniectomy used for keyhole approach to selective amygdalohippocampectomy. The continuous line indicates the position of the scalp incision and the dotted line that of the intended craniectomy.

\section{SELECTIVE AMYGDALOHIPPOCAMPECTOMY (AHC)}

This procedure was introduced by Niemeyer in the mid 1950s and represented a significant departure from the standard temporal lobectomy which was in vogue at that time. Niemeyer ${ }^{42,43}$ suggested a transcortical transventricular approach through the second temporal gyrus to reach the hippocampus and the amygdala.

Considerable interest was raised for selective AHC after Yasargil developed a different approach to perform the procedure by using the transsylvian route. ${ }^{44}$ In Yasargil's technique, the arachnoid over the Sylvian fissure is divided and the bottom of the circular sulcus exposed. An incision is made between two opercular temporal arteries, the temporal peduncle is transected and the ventricular horn exposed. The hippocampal formation is then resected by an extrapial approach as far laterally as the collateral fissure. The amygdala is removed by subpial aspiration.

More recently, Hori has preconized a subtemporal approach through the paraphippocampal gyrus, a technique which entalis significant retraction. ${ }^{45}$

Over the years at the MNI, we have used various modalities of transcortical approaches, initially through the first temporal gyrus, later through the superior temporal sulcus and, for many years now, through the second temporal gyrus, an approach similar to that suggested by Niemeyer. ${ }^{46,47}$ The originality of the technique to be described resides in the strictly endopial resection of the hippocampal formation and amygdala and the use of computer image guidance to perform the procedure.

\section{SURGICAL TECHNIQUE}

\section{Image guided technique for selective AHC}

Since 1992, all selective AHC procedures have been performed using MRI-based frameless stereotaxy. ${ }^{48-50}$ All aspects of the surgery are enhanced with the use of image guidance. The coregistration of a series of anatomical landmarks 


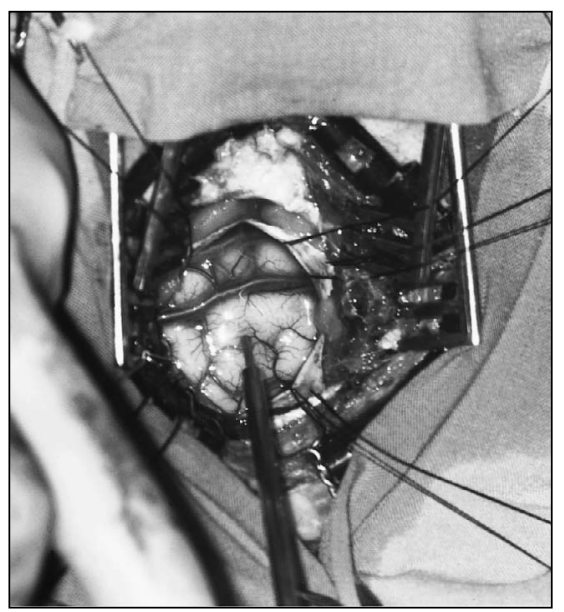

Figure 2: Cortical exposure obtained from keyhole approach. The stereotactic pointer is used to indicate the upper border of the second temporal gyrus and location along its antero-posterior extent. Note presence of a vein running over the superior temporal sulcus.

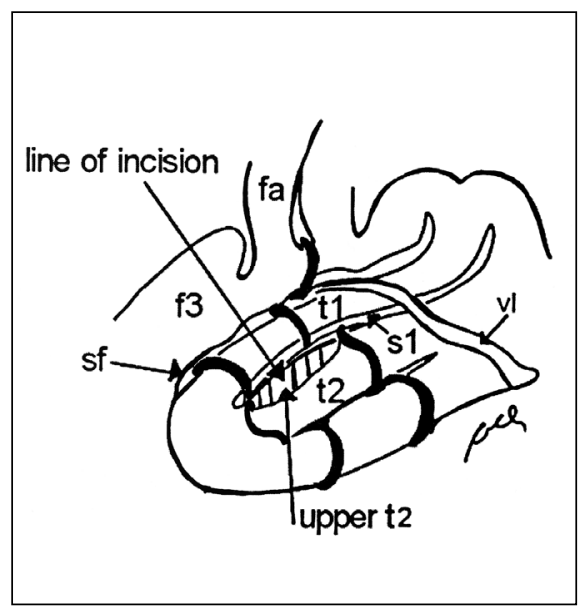

Figure 3: The corticectomy is placed in the T2 gyrus, anterior to the central sulcus in the nondominant temporal lobe and anterior to the precentral sulcus in the dominant hemisphere. (refer to Figure 2). fa=precentral gyrus, $f 3=3 r d$ frontal gyrus, sf=sylvian fissure, $t 1=1$ st temporal gyrus, $t 2=2$ nd temproal gyrus, s1=superior temporal sulcus, vl=vein of Labbé

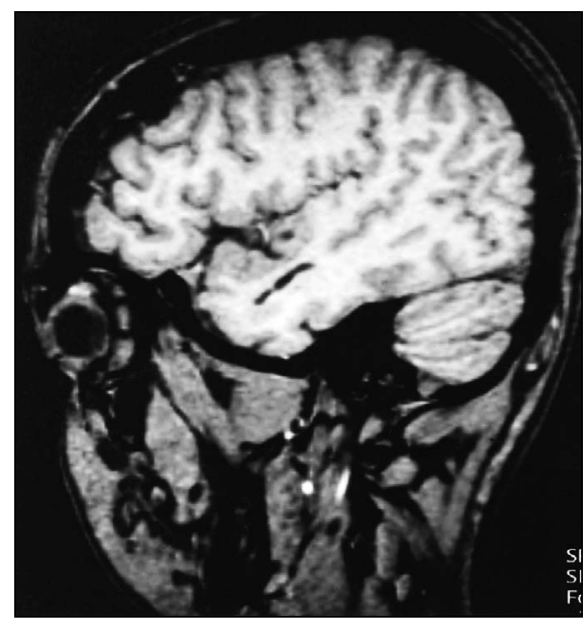

Figure 4: Sagittal MRI after transcortical selective AHC which demonstrates the corridor to the mesial temporal structures. (canthi of the eyes, supratragal point of both ears and, at times, some scalp profiles) provides the interface or match between the patient's head and its virtual image. The technique can be used to optimize the extent and size of both the scalp incision and the craniotomy. The brain anatomy can be displayed in 2D and 3D formats to plan the approach. The position and configuration of the amygdala and hippocampus are first established. Preliminary location of the cortical incision and its relationship to the central area is then determined prior to the scalp incision. The planned trajectory or corridor to the temporal horn can be displayed using the trajectory mode of the image guidance system. The stereotactic pointer is used repeatedly during the procedure to confirm anatomical landmarks and to assess the extent of the resection. Computer guidance and registration has been particularly useful to label and display the position of the ECoG electrodes on a screen for the benefit of the electroencephalographers. A stereotactic trajectory mode provides for accurate placement of depth electrodes directed at the amygdala and hippocampus, a procedure which used to be done free hand with considerably less precision. The exact sites of epileptic activity can be displayed over the brain reconstructions and easily archived. In selective AHC there is no need for cortical stimulation, since the $3 \mathrm{D}$ reconstruction readily identifies the position of the Sylvian fissure and of the central sulcus, which are the main landmarks to delineate the cortical incision.

\section{Standard pterional approach}

When an electrocorticogram is planned, or a larger cortical exposure is desired, a question mark scalp incision is routinely used for the selective AHC. The lower limb starts at the zygoma and curves above the ear to its posterior margin and the superior limb goes forward above the temporalis muscle. The bone opening is fashioned to expose the temporal surface from the pole to the level of the central area posteriorly, including the lower central area and F3, in order to provide an adequate coverage for ECoG.

The need for ECoG in selective AHC is questionable. Because of the limited exposure, recording is practically confined to the temporal lobe. However, by placing multicontact depth electrodes in the amygdala and hippocampus and four rows of four electrodes on the neocortical surface, further confirmation of the epileptogenicity of the limbic structures may be obtained. Some spiking is often seen on the cortex but the overwhelming abnormal activity should be in the mesial structures. The EEG activity may be enhanced with IV Brietal (Brietal sodium, Eli Lilly) injection if the findings are not clear.

We have discontinued the postoperative ECoG after having confirmed the findings of Niemeyer for a transient increase in spiking over the surface after selective AHC. ${ }^{51}$

\section{Keyhole craniotomy}

In patients with clear cut mesial temporal epilepsy, a more selective exposure may be performed. With this approach, image guidance is essential to delineate the location of the cranial opening in relation to the cortical incision. A linear scalp incision starting at the zygoma and curving slightly backwards is used (Figure 1). The temporal muscle is split along its fibers and held with a self-retaining retractor. A burr hole and craniectomy is made through the temporalis muscle and centered over the second temporal gyrus (Figure 2). Under image guidance at all times, the cortical incision is placed just below the superior temporal sulcus and in front of the central sulcus. On the dominant side, the incision should be placed in front of the posterior limit of the precentral sulcus. It is always useful to know about the venous drainage pattern over the Sylvian region and this is obtained with MRI angiography and/or double dose gadolinium scan. 


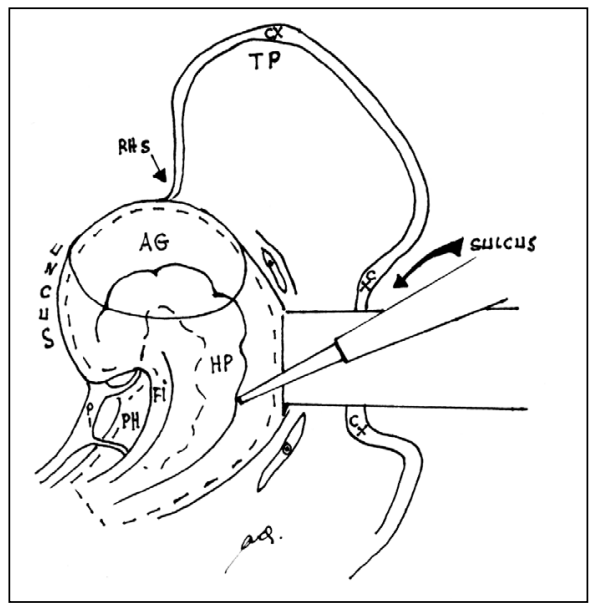

Figure 5: The ultrasonic dissector is used to fashion a corridor to the temporal horn. Opening the ependyma provides an adequate exposure of the amygdala and hippocampal complex. $A G=$ amygdala, $H P=$ hippocampus, Fi=fimbria, $\quad P H=$ parahippocampus, $R H S=$ rhinal sulcus. $P 1=$ posterior cerebral artery, $C X=$ cortex,$T P=$ temporal pole.

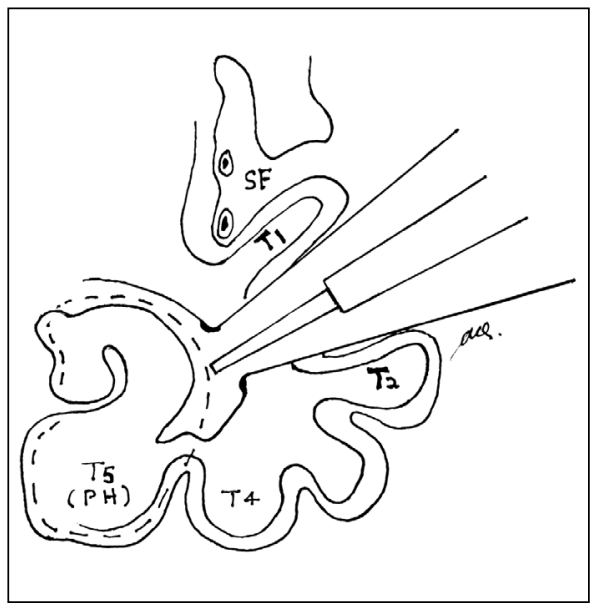

Figure 6: A self-retaining retractor has been installed. The dotted line indicates the intended extent of resection. $S F=$ Sylvian fissure, T1, T2, T4, T5 = 1st, 2nd, 4th and 5th temporal gyri. T5 corresponds to the parahippocampal gyrus $(\mathrm{PH})$.

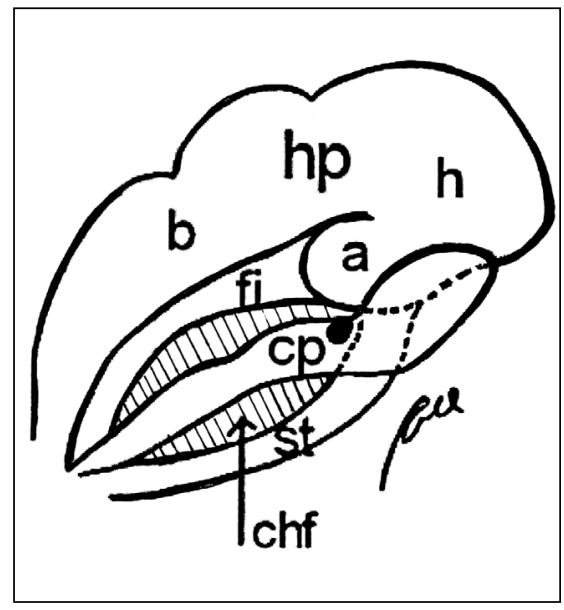

Figure 7: The choroidal fissure (chf) and choroid plexus (cp) are bordered by the fimbria (fi) and stria terminalis (st). The fimbria and stria terminalis come together at the anterior extent of the choroidal fissure at the apex of the uncus or intralimbic gyrus (a) $h$ and $b$ are head and body of the hippocampus. Manipulation of the choroid plexus is essential to recognize the above structures.

\section{Cortical incision}

A keyhole incision measuring 2 to $3 \mathrm{~cm}$ is made either within the depth of the first temporal sulcus (S1) or, preferably, along the upper border of the second temporal gyrus (T2) just below the sulcus and in front of the central sulcus (Figures 3-4). We came to the conclusion that there is no advantage in using the intrasulcal approach. Although the extent of the corridor is reduced with the sulcal approach, it turns out that the cortex is only protected by a thin layer of pia and this is more likely to cause ischemic changes in the cortex due to retraction.

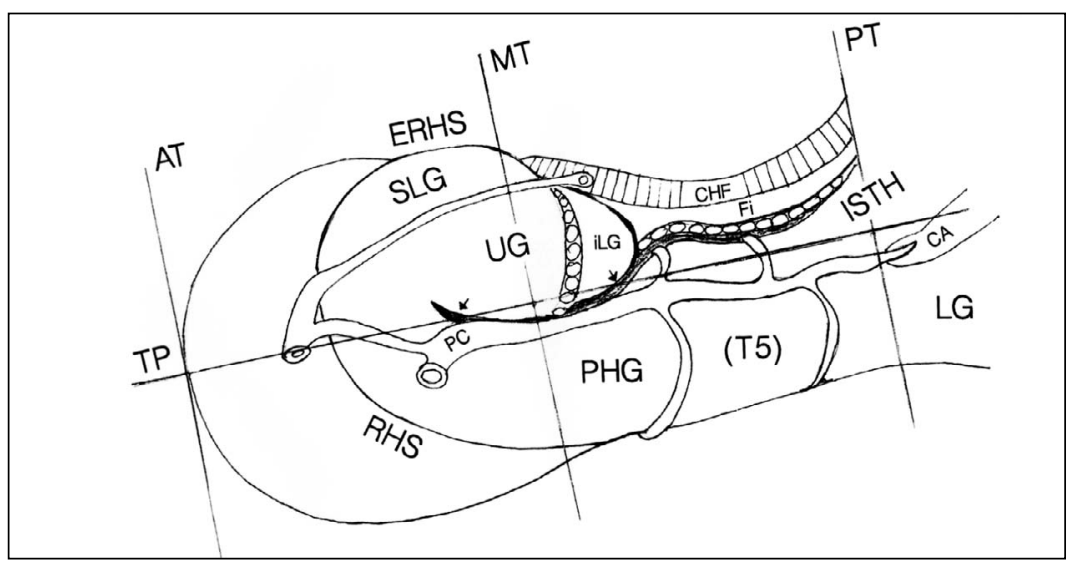

Figure 8: Diagram showing the anatomical structures of the mesial temporal area. $T P=$ temporal pole, $M I=$ horizontal segment of the middle cerebral artery, $A C=$ anterior choroidal artery. The course of the posterior cerebral artery is indicated by the double dotted line, $2=$ optic nerve, $3=$ third cranial nerve, $H P=$ hippocampus, $F i=$ fimbria, $P H G=$ parahippocampal gyrus, $C P=$ cerebral peduncle. The free edge of the tentorium is indicated by the two arrows.

Figure 9: View of the amygdalo-hippocampal complex from the mesial surface of the temporal lobe. Important vascular structures are seen coursing through the ambiens and lateral mesencephalic cisterns and are intimately related with the mesial temporal structures. CHF=choroidal fissure, ERHS=endorhinal sulcus, Fi=fimbria, iLG=intralimbic gyrus, ISTH=isthmus, $L G=$ lingual gyrus, $P C=$ posterior cerebral artery, $P H G=$ parahippocampal gyrus, $R H S=$ rhinal sulcus, $S L G=$ semilunar gyrus, $U G=$ uncinate gyrus. Note branches of posterior cerebral artery entering hippocampal sulcus. AT, MT and $P T=$ anterior, mid and posterior temporal planes. $T P=$ transverse temporal plane 


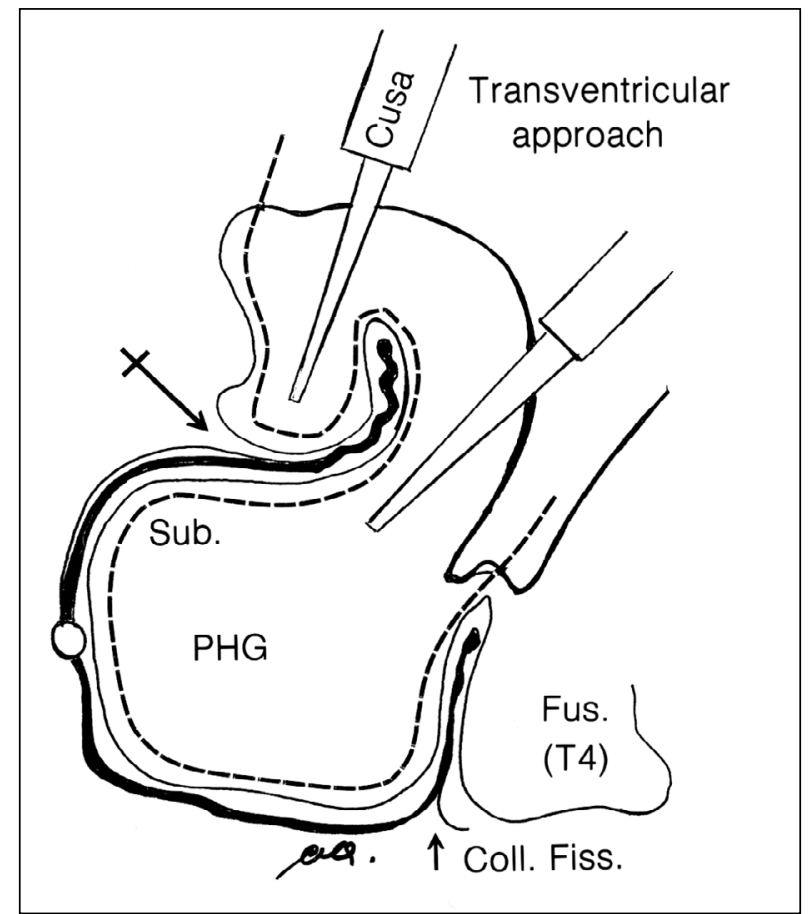

Figure 10: Subpial dissection and endopial aspiration of the hippocampal formation is accomplished with the ultrasonic dissector (CUSA) set at very low parameters of vibration and suction. The entrance to the hippocampal sulcus is indicated with the arrow. This sulcus and its vascular content represent a crucial landmark for the procedure. The collateral fissure (coll. fiss.) should also be identified. Sub = subiculum, Fus = fusiform or 4th temporal gyrus (T4). Note position of posterior cerebral artery indicated by a circle on the mesial side of the parahippocampal gyrus $(P H G)$.

Furthermore, there is often a vein running over and parallel to the sulcus which is a nuisance (Figure 2). By using an ultrasonic dissector (CUSA, Valey Lab, Co) a corridor of approximately 4$5 \mathrm{~mm}$ in height is fashioned down to the ependymal lining which is opened with the same instrument (Figure 5). The more superficial extent of this corridor is created by a subpial dissection along the inferior wall of the superior sulcus which leads in the direction of the temporal horn. A specially-designed, self-retaining retractor is then inserted which provides an unobstructed view of the temporal horn and of the hippocampus proper (Figure 6).

A series of anatomical landmarks for the hippocampal removal should then be recognized in a stepwise fashion. First the lateral ventricular sulcus located between the hippocampus proper and the collateral emninence on the lateral wall of the horn is identified (Figure 6). Then the fimbria and the apex of the uncus (intralimbic gyrus) are visualized on the inner side by lifting the choroid plexus upwards and backwards (Figure 7). This manoeuvre also provides exposure of the choroid fissure, especially of its anterior border which is made by the junction of the fimbria and stria terminalis (Figure 7). The ventricular lining must be opened sufficiently to see the bulge of the amygdala and the anterior-most extent of the horn represented by a point anterior and mesial to the hippocampus. Enough unroofing of the ventricle must be done in order to visualize the tail of the hippocampus. The resection proper is done by entering the parahippocampal gyrus, located underneath the hippocampus, over and along the lateral ventricular sulcus. An endopial intragyral removal of the parahippocampal gyrus is then performed along its antero-posterior extent (Figures 6-10). In dissecting the cortex mesially within the parahippocampal gyrus, care is taken not to injure the posterior cerebral artery which runs over its mesial border (Figures 8-9). It can be visualized through the pia. Dissection is then carried out forward into the parahippocampal gyrus and the anterior portion of the uncus is entered. The hippocampus proper is then tilted laterally into the empty cavity of the parahippocampal gyrus revealing the fimbria which is resected along its length exposing the medial side of the hippocampal fissure which corresponds to the dentate gyrus. The hippocampus proper is transected at the junction of the body and the tail and then lifted up and forward exposing the perforating arterioles arising from the hippocampal artery proper located within the hippocampal sulcus. The hippocampal sulcus is an essential landmark and must be identified and visualized during the entire course of the procedure. Holding this sulcus with a forceps allows the surgeon to identify the various subcompartments of the hippocampal formation namely the parahippocampal gyrus, the subiculum, the hippocampus proper and the dentate gyrus (Figures 6, 10). The vessels within the sulcus are coagulated and divided or simply teased out of the sulcus. The fimbria is then subpially resected forward into the apex of the uncus (intralimbic gyrus). At this point, the content of the anterior portion of the uncus is also resected by a subpial aspiration, care being taken not to endanger the cerebral peduncle or the third nerve which can be seen through the pia (Figure 8). The entire content of the uncus is emptied, including the segment which fills the basal cisterna. Extreme care should be taken to identify the dorso-mesial extent of the amygdala, which corresponds to the endorhinal sulcus, in order to perform a radical removal of the amygdala itself. A reliable landmark in this area is the entrance of the anterior choroidal artery into the ventricular cavity, where it fans out to form the choroidal plexus (choroidal point) (Figure 7). Note that the anterior choroidal artery and the optic tract run together within the endorhinal

Table 1: Initial seizure outcome of all patients compared with the outcome after 10 patients underwent reoperation.

\begin{tabular}{|c|c|c|}
\hline \multicolumn{3}{|c|}{$\begin{array}{c}\text { Selective AHC } \\
150 \text { patients }>6 \text { months f/up }\end{array}$} \\
\hline Classification & Outcome \% & After reoperation $\%$ \\
\hline Class $1($ red $100 \%)$ & 81 & 84 \\
\hline Class $2($ red $>90 \%)$ & 8 & 11 \\
\hline Class $3(60-90 \%)$ & 4 & 4 \\
\hline Class $4(<60 \%)$ & 7 & -1 \\
\hline Class 5 (worse) & 0 & 0 \\
\hline AURA & & \\
\hline Documented & & \\
\hline Stopped & & \\
\hline
\end{tabular}


Table 2: Reoperation after a selective AHC

\begin{tabular}{|c|c|c|c|c|}
\hline \multicolumn{5}{|c|}{10 patients $>6$ months f/up } \\
\hline Patient & $\begin{array}{l}\text { Type } \\
\text { 1st op. }\end{array}$ & $\begin{array}{c}\text { No. months } \\
\text { later }\end{array}$ & $\begin{array}{c}\text { Type } \\
\text { 2nd op. }\end{array}$ & $\begin{array}{c}\text { Class/ } \\
\text { Outcome }\end{array}$ \\
\hline $\mathrm{RD}$ & SAHC & 17 & SAHC & 1 \\
\hline QX & SAHC & 7 & SAHC & 1 \\
\hline GI & SAHC & 21 & SAHC & 1 \\
\hline $\mathrm{AK}$ & SAHC & 74 & C.Hipp. & 2 \\
\hline QI & Sel.Amyg. & 67 & SAHC & 2 \\
\hline $\mathrm{KE}$ & SAHC & 34 & $\mathrm{CAH}$ & 1 \\
\hline EQ & SAHC & 19 & $\mathrm{CAH}$ & 1 \\
\hline CI & SAHC & 14 & $\mathrm{CAH}$ & 2 \\
\hline $\mathrm{AF}^{*}$ & SAHC & 45 & $\mathrm{CAH}$ & 2 \\
\hline IB & R.parietal & 71 & SAHC & 1 \\
\hline
\end{tabular}

* this patient had a first operation for resection of an astrocytoma and 15 months later had a Sel.AHC

Sel.Amyg. $=$ selective amygdalectomy

$\mathrm{CAH}=$ cortical amygdalohippocampectomy

SAHC $=$ selective amygdalohippocampectomy

C.Hipp = cortical hippocampectomy

R. parietal $=$ right parietal corticectomy

sulcus and can be seen through its pial lining. If further resection of the posterior extent of the hippocampus and parahippocampal gyrus is desired, it is done by subependymal and endopial aspiration backwards in the direction of the tectal cisterna, along the cerebral peduncle and the P2 segment of the posterior cerebral artery. The habitual posterior limit of the hippocampal formation resection corresponds to the lateral mesencephalic sulcus which runs vertically on the side of the midbrain between the cerebral peduncle and the tectum (Figure 8). Following complete hemostasis, the self-retaining retractor is removed and any devascularized area of the cortex is resected. Figures 4 (sagittal), 11 (coronal) and 12 (transverse) show a typical postoperative appearance of the surgical resection.

\section{Results ON SEIZURE TENDENCY (TABLES 1, 2 \& 3)}

Because some of the patients treated by selective AHC have undergone a reoperation (10 patients) which has consisted of

Table 3: Postoperative medication

\begin{tabular}{lc}
\hline \multicolumn{2}{c}{ Selective AHC } \\
164 procedures $>$ 6 & months f/up \\
Postoperative Medication & $\%$ \\
None & 25 \\
Being tapered & 27 \\
Less & 24 \\
Same & 28 \\
Different & 5 \\
More & 1 \\
\end{tabular}

either an extension of the selective AHC (five patients) or a conversion of a selective AHC into a CAH (corticoamygdalohippocampectomy) (five patients) [Table 2], we have considered 4 groups for the evaluation on seizure tendency. First the total number of patients who initially had a selective AHC [Table 1]. Second the group of patients who had a selective AHC followed again by a selective AHC (extension completion) [Table 2]. Thirdly, those patients who had a conversion into a CAH [Table 2]. Finally, we have considered the patients who had only one operation [Table 1].

\section{Complications (TABle 4)}

Complications have been few. There was one case of scalp and bone infection and no case of subdural empyema.

Three patients who were operated on the dominant side have developed transient dysphasia. One of these had a significant anomia for three weeks. It is assumed, but not clear, that these were related to the positioning of the cortical incision, to ischemic devascularization at the edge of the cortical incision or to retraction itself. One patient harbouring a ganglioglioma developed a transient 3rd nerve paresis.

\section{Pitfalls of Selective AHC}

The primary pitfall of selective AHC is to use this procedure when the seizure focus is located in the neocrotex and does not involve primarily the limbic structure. This should be suspected when the hallmark of mesial sclerosis, i.e. hippocampal atrophy and sclerosis, are not seen on MRI or when the seizure pattern is suggestive of neocortical onset i.e. characterized by sensorimotor, auditory or convulsive phenomena.

Another pitfall would be to perform an incomplete AHC. Adequate exposure and knowledge of the surgical anatomy should result in a radical resection of the amygdala i.e. of more than $4 / 5$, the residual tissue being in the dorsal portion of the amygdala where boundaries are harder to establish. Furthermore, the junctional zone between the amygdala and hippocampus, including the ventral portion of the uncus and intralimbic gyrus (apex of uncus), should be resected. Finally, the resection of the "hippocampus" should not be limited to the hippocampus proper but must involve the dentate gyrus and the parahippocampal gyrus. Completeness of the hippocampal resection should not be evaluated in a linear fashion but also "circumferentially" around the hippocampal fissure.

Table 4: Selective AHC complications

\begin{tabular}{lc}
\hline \multicolumn{2}{c}{164 procedures } \\
Complications & Number \\
Subgaleal effusion & 1 \\
Otitis & 6 \\
Scalp infection & 1 \\
Abscess & 1 \\
Brain swelling & 1 \\
3rd Nerve paresis & 1 \\
Transient dysphasia & 3 \\
\end{tabular}




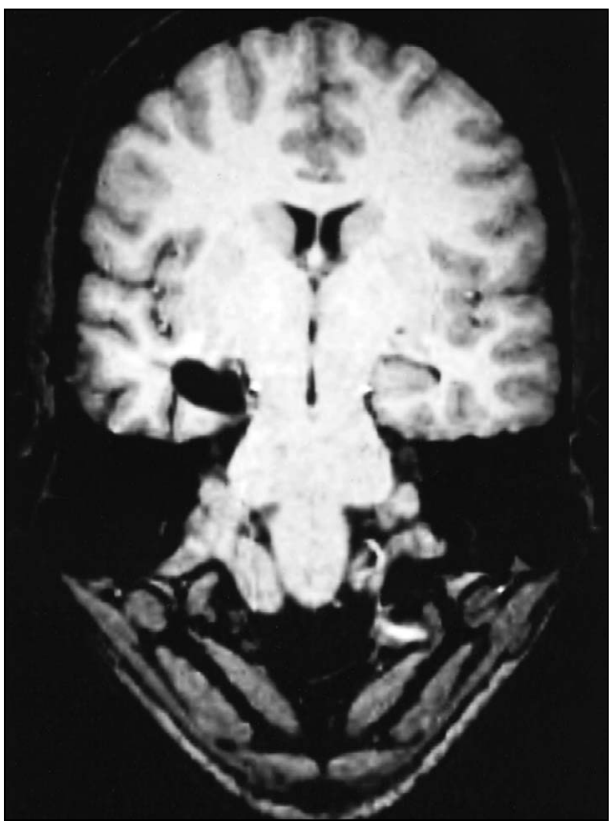

Figure 11: Postoperative coronal MRI showing removal of the hippocampus and most of the parahippocampal gyrus.

To avoid potential complications, a number of pitfalls related to temporal lobe surgery should be recognized. A successful surgery relies on an effective exposure. The most common mistake is inadequate inferior and anterior temporal exposure. The lower central point, i.e. the lower extent of the central sulcus, must be reliably identified for localizing the corticectomy. This can be accomplished with the 3D surface reconstruction and image guidance. There is nothing to be gained by making the cortical incision too short. It must measure $2-3 \mathrm{~cm}$ in length to get a freer and easier access to the temporal horn. On the dominant side it must be located in front of the lower central point and preferably in front of the precentral sulcus. This places the cortical incision within the boundaries of the standard temporal resection which is not associated with speech disturbances if the bypassing vessels are respected.

The temporal horn is $3 \mathrm{~cm}$ from the surface of T2 and usually in the direction of the superior temporal sulcus but an errant trajectory can lead the surgeon to miss the temporal horn in the dissection through the white matter. A too anterior trajectory will pass by the anterior extent of the ventricle and a too dorsal one could lead into the insula or temporal stem. It is best to err inferiorly and follow the grey matter of the collateral sulcus to the ventricle.

In the endopial removal of the mesial structures, the CUSA is used with low parameters of suction and vibration (12\% and .12) to prevent tearing the pial layer. In the endopial emptying of the parahippocampal gyrus, care must be taken to maintain the integrity of the pia to protect the structures of the ambiens cisterna and specifically the posterior cerebral artery. Similarly, in resecting the structures located medial and anterior to the hippocampal sulcus and corresponding to the dentate gyrus and velum terminale, the pia of the ambiens cisterna must be

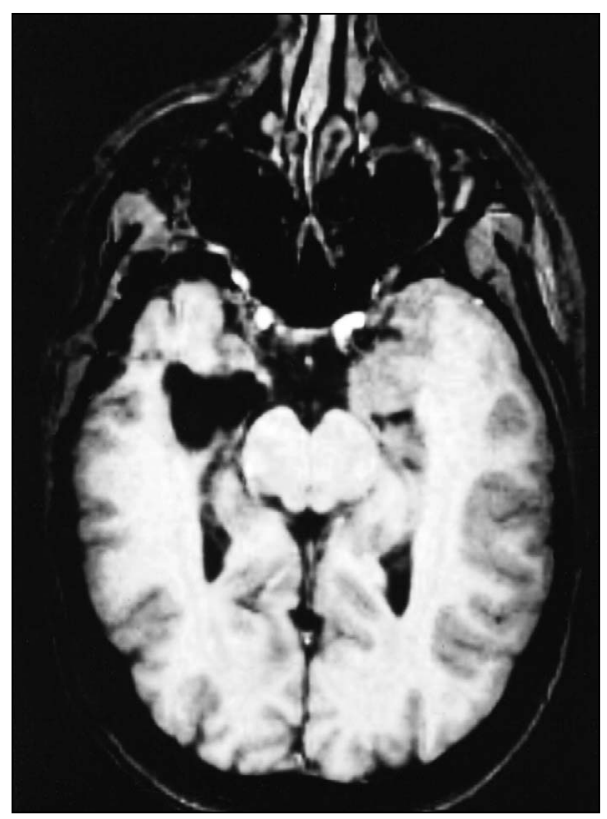

Figure 12: Postoperative transverse MRI showing resection of the amygdala and anterior hippocampus. Note the preservation of the pia along the border of the cerebral peduncle and basal cisterna.

recognized and left undisturbed in order to avoid damage to the midbrain. Finally, in emptying the lower portion of the uncus below the incisura, the 3rd nerve should be recognized and left undisturbed.

Whenever the anatomy remains or becomes unclear, the surgeon must back up and retrieve the more obvious anatomical landmarks such as the choroid plexus, the lateral sulcus or the free edge of the tentorium. By using ultrasonic dissection, hemostasis is usually not a problem and coagulation is not necessary.

\section{DiscuSsION}

In 1954, Penfield ${ }^{8}$ indicated that, on the basis of a second operation, further hippocampal removal could transform a failed operation into a successful one. In the ensuing years, instead of pursuing the idea of removing the hippocampus in a more radical fashion, the trend was to do a "temporal lobectomy" with sparing of the hippocampus. This approach stemmed from the work of Scoville and Milner ${ }^{52}$ and Penfield and Milner ${ }^{53}$ which stressed the risk for memory after bilateral hippocampal damage. Nevertheless, by 1958 , Niemeyer ${ }^{42,43}$ had suggested a selective removal of the amygdala and hippocampus on the basis of available clinical and experimental evidence for the crucial role of the amygdala and hippocampus in seizures of temporal lobe origin. Feindel, studying Penfield's material, had also demonstrated the paramount role played by the amygdala in the temporal lobe automatisms and seizures.., 7

The standard procedure for temporal resection used in most centres had been an "en bloc" resection, advocated among others by M. Falconer ${ }^{38}$ and later by Polkey in England ${ }^{54}$ and Crandall ${ }^{55}$ in the United States. At the MNI, the standard technique has been that of an anterior temporal resection including the amygdala and 
the anterior hippocampus (Figure 11). This approach departed from the "en bloc" resection due to the fact that it was carried out mainly as a subpial aspiration of the mesiobasal structures. Until the mid 70s, and in the hands of Rasmussen, the extent of hippocampal resection was based mainly on the degree of epileptiform activity detected during ECoG following initial removal, and could vary from an anterior to a total removal of the hippocampus. At the MNI, this author, in an initial series of 200 consecutive cases done between 1971 and 1981, developed a standard approach to temporal resection where a maximum of $4.5 \mathrm{~cm}$ of cortex, was removed along the Sylvian fissure, usually combined with a resection of 1.5 to $2 \mathrm{~cm}$ of the hippocampus. In 1984 , Spencer, in a series of 36 patients, also suggested that the resection of lateral cortex should be limited to $4.5 \mathrm{~cm}$ over the lateral cortex and recommended a radical removal of the hippocampus through this limited anterior resection. ${ }^{56}$

Our work with chronic depth electrode recording has confirmed the overwhelming predominance of temporal seizure onset from limbic structures. ${ }^{28,30,33}$ In patients with bitemporal epilepsy it has been shown that the seizures arise predominantly from one temporal lobe and usually from the amygdala or hippocampus in over $80 \%$ of the time. ${ }^{33}$ Seizures of neocortical onset have been relatively rare but well documented. We have extensively used the technique of preoperative sphenoidal recording ECoG with surface and depth electrodes to define the level of onset of seizures. Combining these approaches and relying more and more heavily on the morphological changes seen in the limbic structures on MRI, we have carried out more and more frequently the transcortical selective AHC which has become the procedure of choice in cases of mesio-temporal limbic epilepsy, i.e. when the seizure pattern, the EEG findings and the morphological stigmata are congruent.

\section{INDICATION FOR SELECTIVE AHC: WHY SELECTIVE AHC RATHER THAN CORTICOAMYGDALOHIPPOCAMPECTOMY (CAH)?}

Corticoamygdalohippocampectomy $(\mathrm{CAH})$ or the anterior temporal resection, or what is sometimes inappropriately called a temporal lobectomy, remains an appropriate technique to treat temporal epilepsy. It has not been convincingly demonstrated that the neuropsychological impact of these operations is greater or lesser than for selective AHC. However, it remains that if the site of origin of the seizures resides in the damaged structures then these should be resected as radically and selectively as possible. The larger cortical removal in standard resection should not become, or remain, simply a method of exposing the limbic structures. Finally, the transcortical selective approach has the great advantage of minimizing or completely abolishing the impact of dividing several venous and arterial adhesions which are tedious, time consuming and, at times, associated with some degree of cerebral swelling.

\section{CONCLUSION}

Temporal resections are no longer considered as a single standard type of resective procedure. The temporal "en bloc" lobectomy may still have its place in specific instances. However, the advances in intracranial recording and brain imaging, as well as consideration of patients with impaired memory, has imposed upon the surgeon the need to consider various types of resections individualized for each specific patient. Over the last 15 years there has been a definite trend in reducing the extent of neocortical resection and increasing the amount of limbic structures removal. This has led surgeons in many centres to use, more and more frequently, selective limbic removal by a variety of approaches. We have found that the transcortical T2 or transsulcal S1 approach was entirely satisfactory from the anatomical and technical standpoints and allowed the use of an ultrasonic dissector to perform the endopial AHC. This technique is strictly a transcortical, transventricular procedure and minimizes the manipulations of the Sylvian vessels and brain stem. In our series, if a proper selection of patients has taken place, the neurological complications have been minimal and the result on seizure tendency very high.

\section{ACKNOWLEDGEMENT}

The contributions of Drs. Hans McLelland and Warren Boling to the preparation of this paper are appreciated.

\section{REFERENCES}

1. Jackson JH, Colman WS. Case of epilepsy with tasting movements and "dreamy state" with very small patch of softening in the left uncinate gyrus. Brain 1898;21: 580-590.

2. Kaada BR. Somatomotor, autonomic and electrographic responses to electrical stimulation of "rhinencephalic" and other structures in primates, cat and dog: a study of responses from limbic, subcallosal, orbito-insular, pyriform and temporal cortex, hippocampus, fornix and amygdala. Acta Physiol Scand 1951;Suppl 83:1-285.

3. Vigouroux R, Gastaut HR, Badier M. Provocation des principales manifestations cliniques de l'épilepsie dite temporale par stimulation des structures rhinencéphaliques chez le chat nonanaesthésié. Rev Neurol 1951;85:505-508.

4. Gastaut HR, Vigouroux R, Naquet R. Lésions épileptogènes amygdalo-hippocampiques provoquées chez le chat par l'injection de "crème d'albumine". Rev Neurol 1952;87:607-609.

5. Green JD, Shimamoto T. Hippocampal seizures and their propagation. Arch Neurol Psychiatr 1953;71: 687-702.

6. Feindel W, Penfield W. Localization of discharge in temporal lobe automatism. Arch Neurol Psychiatr 1954;72: 605-630.

7. Feindel W, Penfield W, Jasper H. Localization of epileptic discharge in temporal lobe automatism. Trans Am Neurol Assoc 1952;14-17.

8. Penfield W, Jasper H. Epilepsy and the functional anatomy of the human brain. Boston: Little Brown, 1954.

9. Morris AA. Temporal lobectomy with removal of uncus, hippocampus and amygdala. Arch Neurol Psychiatr 1956;76: 479-496.

10. Corsellis JAN. The incidence of Ammon's horn sclerosis. Brain 1957;80: 193-208.

11. Earle KM, Baldwin M, Penfield W. Incisural sclerosis and temporal lobe seizures produced by hippocampal herniation at birth. Arch Neurol Psychiatr 1953;69: 27-42.

12. Sano K, Malamud N. Clinical significance of sclerosis of the cornu ammonis. Arch Neurol Psychiatr 1953;70: 40-53.

13. Babb TL. Research on the anatomy and pathology of epileptic tissue. In: Lüders H, ed. Epilepsy Surgery. New York: Raven Press, 1991; 719-727.

14. Cadilhac J. Hippocampe et épilepsie. Montpellier, Imprimerie Paul Dehan, 1955; 205.

15. Gale K. Subcortical structures and pathways involved in convulsive seizure generation. J Clin Neurophysiol 1992;9(2): 264-277.

16. Houser CR, Miyashiro JE, Swartz BE, et al. Altered patterns of dynorphin immunoreactivity suggest mossy fiber reorganization in human hippocampal epilepsy. J Neurosci 1990;10:267-282.

17. Sato M, Racine RJ, McIntyre DC. Kindling: basic mechanisms and clinical validity. Electroencephalogr Clin Neurophysiol 1990;76: 459-472. 
18. Scheibel ME, Scheibel AB. Hippocampal pathology in the temporal lobe epilepsy. A Golgi Study. In: Brazier MAB, ed. Epilepsy, its Phenomena in Man. UCLA Forums in Medical Sciences. New York \& London: Academic Press, 1973; 17.

19. Sloviter RS. The functional organization of the hippocampal dentate gyrus and its relevance to the pathogenesis of temporal lobe epilepsy. Ann Neurol 1994;35: 640-654.

20. Sutula T, Cascino G, Gavazos J, Parada I, Ramirez L. Mossy fiber synaptic reorganization in the epileptic human temporal lobe. Ann Neurol 1989;26: 321-330.

21. Kim H-I, Olivier A, Jones-Gotman M, Primrose D, Andermann F. Corticoamygdalectomy in memory-impaired patients. Stereotact Funct Neurosurg 1992;58: 162-167.

22. Price JL, Russchen F, Amaral DG. The amygdaloid complex. In: Bjorklund A, Hokfelt T, Swanson LW eds. Handbook of Chemical Neuroanatomy. Vol. 5. Amsterdam: Elsevier, 1987;279-388.

23. Swanson LW, Kohler C, Bjorklund A. The limbic region. In: Bjorklund A, Hokfelt T, Swanson LW, eds. The Septohippocampal system: Handbook of Chemical Neuroanatomy. Vol. 5. Integrated Systems of the CNS, Part 1. Amsterdam: Elsevier, 1987;125-277.

24. Rasmussen T, Branch C. Temporal lobe epilepsy. Indications for and results of surgical therapy. Postgrad Med J 1962;31: 9-14.

25. Gloor P, Olivier A, Quesney LF, et al. The role of the limbic system in experimental phenomena of temporal lobe epilepsy. Ann Neurol 1982;12(2):129-144.

26. Ives JR, Thompson CJ, Gloor P, Olivier A, Woods JF. The on-line computer detection and recording of spontaneous temporal lobe epileptic seizures from patients with implanted depth electrodes via a radiotelemetry link. EEG J 1974;37:199-213.

27. Olivier A. Relevance of removal of limbic structures in surgery for temporal lobe epilepsy. Can J Neurol Sci 1991;18: 628-635.

28. Olivier A, Gloor P, Ives JP. Stereotaxic seizure monitoring in patients with "bitemporal epilepsy". Indications, techniques and results. Proc Am Assoc Neurol Surg 1977;14.

29. Olivier A, Gloor P, Ives J. Investigation et traitement chirurgical de l'épilepsie bitemporale. L'Union Médicale 1980;109: 1-4.

30. Olivier A, Gloor P, Quesney LF, Andermann F. The indications for and the role of depth electrode recording in epilepsy. Appl Neurophysiol 1983;46:33-36.

31. Quesney LF. Clinical and EEG features of complex partial seizures of temporal lobe origin. Epilepsia 1986;27(suppl 2): S27-S45.

32. Quesney LF, Olivier A, Andermann F, et al. EEG and clinical manifestations of frontal and temporal lobe seizures. Can J Neurol Sci 1987;14:252-253.

33. So N, Gloor P, Quesney LF, et al. Depth electrode investigations in patients with bitemporal epileptiform abnormalities. Ann Neurol 1989;25: 423-431.

34. So N, Olivier A, Andermann F, et al. Results of surgical treatment in patients with bitemporal epileptiform abnormalities. Ann Neurol 1989;25: 432-439.

35. Halgren E, Walter RD, Cherlow DG, Crandall PH. Mental phenomena evoked by electrical stimulation of the human hippocampal formation and amygdala. Brain 1978;101:83-117.

36. Berkovic SF, Andermann F, Olivier A, et al. Hippocampal sclerosis in temporal lobe epilepsy demonstrated by magnetic resonance imaging. Ann Neurol 1991;29: 175-182.

37. Wieser HG, Engel J, Jr. Williamson PD, Babb TL, Gloor P. Surgically remediable temporal lobe syndromes. In: Engel J Jr. ed. Surgical Treatment of the Epilepsies. Second Edition. New York: Raven Press, 1993;49-63.
38. Falconer MA, Hill D, Meyer A, Mitchell W, Pond DA. Treatment of temporal lobe epilepsy by temporal lobectomy: survey of findings and results. Lancet, 1955;1: 827-835.

39. Abou-Kalil B, Andermann E, Andermann F, Olivier A, Quesney LF. Temporal lobe epilepsy after prolonged febrile convulsions: excellent outcome following surgical treatment. Epilepsia 1993; 34(5): 878-883.

40. Wieser HG. Selective amygdalohippocampectomy: indications, investigative techniques and results. In: Symon L et al, eds. Advances and Technical Standards in Neurosurgery. New York: Wien-Springler, 1986;13: 40-133.

41. Wieser HG, Yasargil MG. Die "Selective amygdohipokampektomie" Als chirurgische behandlungsmethode du mediobasallimbischen epilepsie. Neurochirurgia 1982;25: 39-50.

42. Niemeyer P. The transventricular amygdalohippocampectomy in temporal lobe epilepsy. In: Baldwin $\mathrm{M}$ and Bailey $\mathrm{P}$, eds. Temporal Lobe Epilepsy. Illinois: CC Thomas Springfield, 1958; 461-482.

43. Niemeyer P, Bello H. Amygdalohippocampectomy in temporal lobe epilepsy. Microsurgical technique. Excerpta Medica 1973; 293: 20 (abstr 48).

44. Yasargil MG, Teddy PJ, Roth P. Selective amygdalohippocampectomy: operative anatomy and surgical technique. In: Symon L et al eds. Advances and Technical Standards in Neurosurgery. New York: Springler-Wien, Vol 12, 1985.

45. Hori $T$, Tabuchi $S$, Kurosaki $M$, et al. Subtemporal amygdalohippocampectomy for treating medially intractable temporal lobe epilepsy. Neurosurgery 1993;33(1):50-56.

46. Olivier A. Standardized versus focus resection in the surgery of temporal lobe epilepsy. In: Pawlik G, Stefan H, eds. Focus Localization: Multimethodological Assessment of LocalizationRelated Epilepsy. Berlin, Germany 1996;383-402.

47. Olivier A, Cukiert A, Palomino-Torres X, Andermann F. Transcortical selective amygdalohippocampectomy: microsurgical technique and results. Proc Am Epilepsy Assoc, Seattle December 1992, (abstract)

48. Olivier A, Alonso-Vanegas M, Comeau R, Peters TM. Image guided surgery of epilpesy. Neurosurgery Clin N Am 1996;7(2): 229244.

49. Olivier A, Boling W. Image guided surgery of epilepsy and intrinsic brain tumours. In: Alexander E III, Maciunas RJ, eds. Advanced Neurosurgical Navigation. New York: Thieme, 1998.

50. Olivier A, Germano I, Cukiert A, Peters TM. Frameless stereotaxy for surgery of the epilepsies: preliminary experience. Technical note. J Neurosurg 1994;81: 629-633.

51.Wennberg RA, Quesney LF, Dubeau F and Olivier A. Increased neocortical spiking and surgical outcome after selective amygdalo-hippocampectomy Electroencephalogr Clin Neurophysiol 1998;48:105-111.

52. Scoville W, Milner B. Loss of recent memory after bilateral hippocampal lesions. J Neurol Neurosurg Psychiatry 1957;20:11-21.

53. Penfield W, Milner B. Memory deficit produced by bilateral lesions in the hippocampal zone. Arch Neurol Psych 1958;79:475-497.

54. Polkey CE. Anterior temporal lobectomy at the Maudsley Hospital, London. In: Engel J Jr ed. Surgical Treatment of the Epilepsies. New York: Raven Press, 1989;641-645.

55. Crandall PH. Cortical resections. In: Engel J Jr ed. Surgical Treatment of the Epilepsies. New York: Raven Press, 1987;377416

56. Spencer DD, Spencer SS, Mattson RH, Williamson PD, Novelly RA. Access to the posterior medial structures in the surgical treatment of temporal lobe epilepsy. Neurosurgery 1984;15: 667-671. 